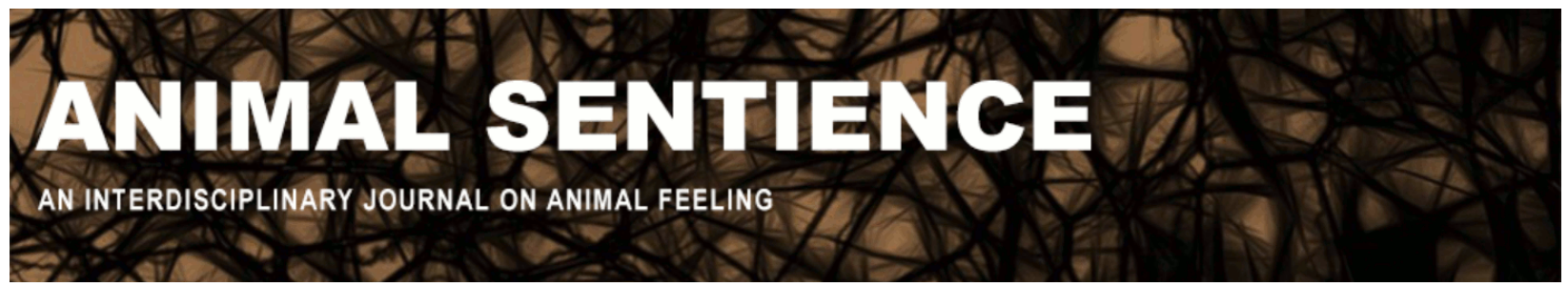

Veit, Walter and Browning, Heather (2021) Extending animal welfare science to include wild animals. Animal Sentience 7(20)

DOI: $10.51291 / 2377-7478.1675$

Date of submission: 2021-06-19

Date of acceptance: 2021-06-23

(c)

This article has appeared in the journal Animal

Sentience, a peer-reviewed journal on animal

cognition and feeling. It has been made open access,

free for all, by WellBeing International and deposited

in the WBI Studies Repository. For more information,

please contact

wbisr-info@wellbeingintl.org.

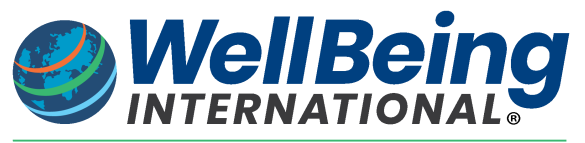

SOLUTIONS FOR PEOPLE, ANIMALS AND ENVIRONMENT 


\title{
Extending animal welfare science to include wild animals
}

\author{
Commentary on $\mathrm{Ng}$ on Animal Suffering
}

\author{
Walter Veit \\ School of History and Philosophy of Science, University of Sydney
}

\section{Heather Browning}

Centre for Philosophy of Natural and Social Science, London School of Economics and

Political Science

\begin{abstract}
Ng's (2016) target article built on his earlier work advocating a science of welfare biology (Ng 1995). Although there were problems with the models proposed in $\mathrm{Ng}^{\prime}$ s original paper regarding the balance of pleasure and suffering for wild animals, his call for a science of wild animal welfare was a sound one. This does not require a new discipline but just an extension of the existing frameworks and methods of animal welfare science to include wild animals.
\end{abstract}

\begin{abstract}
Walter Veit is a PhD candidate in the School of History and Philosophy of Science at the University of Sydney. His dissertation tries to advance the science of consciousness to its post-Darwinian phase by putting the origins, function, and phylogenetic spread of animal consciousness at the center of our investigation. Website

Heather Browning is a former zookeeper and animal welfare officer turned philosopher. Now postdoctoral Research Officer in animal sentience and welfare at the London School of Economics working on conceptual and methodological issues in the measurement of consciousness and animal welfare. Website
\end{abstract}

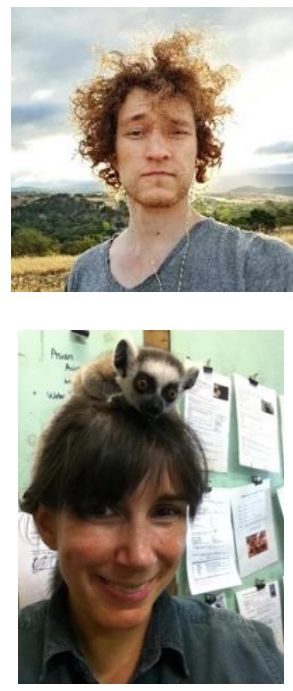

In a 1995 paper entitled "Towards welfare biology: Evolutionary economics of animal consciousness and suffering," the Malaysian-Australian welfare economist Yew-Kwang Ng advocated the creation of an interdisciplinary field of "welfare biology" that he defined as the "study of living things and their environment with respect to their welfare (defined as net happiness, or enjoyment minus suffering)" (p. 255). Ng aimed to address three questions with this field. (1) Which species are sentient? (2) Do their positive experiences outweigh their negative ones? (3) How can their welfare be improved? These three questions are obviously central to Animal Sentience. They are also appealing to any broadly utilitarian thinker; like Ng, we endorse a subjective Benthamite view of welfare as a balance of pleasure and pain (Browning 2019; Veit 2021).

Although these three questions were obviously worth investigating, $\mathrm{Ng}^{\prime}$ 's proposals have received almost no attention from scientists. In contrast, philosophers, ethicists, and animal activists have promoted Ng's idea fervently in recent years (e.g., Horta 2010; Tomasik 2015; 
Johannsen 2020; Soryl et al. 2021) because they perceived a neglect of wild animals in animal welfare science. The latter has historically focused on animals in captivity, especially in farms, and on developing adequate ways to measure animal welfare under captive conditions.

One might get the impression from this that few animal welfare scientists, economists, and biologists (e.g., Beausoleil et al. 2018; Beausoleil 2020; Harvey et al. 2020) have been interested in wild animal welfare, but we think some of the omissions in $\mathrm{Ng}^{\prime}$ s original 1995 paper might also have been an important reason. The paper contained no empirical data and no serious engagement with the work of animal welfare scientists. It proposed a speculative and intuitiondriven model of wild animal welfare, combining evolutionary biology, economics, and population dynamics, to establish what Ng called the "Buddhist Premise" that the balance between suffering and pleasure for wild animals would tilt towards suffering. This presumption of the dominance of suffering in nature was then taken up by other writers in wild animal ethics (e.g. Horta 2010; Tomasik 2015) and led to some quite radical proposals (e.g., about putative moral benefits of habitat destruction; Tomasik 2017). Although Groff and Ng (2019) went on to report errors in the original that countered their Buddhist Premise, the original assumption can still be found in the wild animal ethics and welfare literature.

Ng's (2016) target article, rather than updating his older proposal, proposed some costeffective and pragmatic ways to improve animal welfare. $\mathrm{Ng}$ suggested that we should first focus on the welfare of farmed animals and leave the question of wild animal welfare for the future. This is at variance with the way his original call for a science of welfare biology has been taken up by some animal advocates (Soryl et al. 2021). Ng's reasons were largely pragmatic: it would be easier to win people over to improving farmed welfare because (1) we are the ones causing their suffering, (2) we know less about wild animals, (3) we cannot intervene as directly in their lives, and (4) our interventions in natural ecosystems could have unforeseeable negative repercussions.

Although some commentators uncharitably implied that his interest might focus on farmed animals because they are useful to us, we agree with much of $\mathrm{Ng}^{\prime}$ 's pragmatic reasoning. Even in a utilitarian framework that treats the welfare of all species equally, it could be considered reasonable to postpone the question of wild animal welfare for the future, when we know more and when concern for farmed animals has gained a broader social consensus. Unfortunately, few commentators endorsed this pragmatic position. One notable exception was the philosopher Kyle Johannsen (2016), who concluded his commentary with approbation: "Ng should be commended for his progressive and yet cautious stance towards suffering in the wild, a topic that has only recently begun to attract much philosophical attention." Five years later, however, things have changed a lot. Wild animal welfare is now widely discussed by philosophers, ethicists, animal advocates, and policy-makers, with some of the discussion funded by private non-profit organizations dedicated to animal welfare (Soryl et al. 2021). The science of wild animal welfare once again calls for careful consideration.

The models that were initially proposed for wild animal welfare were highly speculative; but the Darwinian idea of welfare as a natural phenomenon in its evolved context seems useful and worthy of pursuit. In 1998 Marian Dawkins had noted that "animal welfare studies generally lacked the evolutionary framework that characterizes so much else in biology" (p. 305). Soryl et al. propose a welfare biology that moves beyond $\mathrm{Ng}^{\prime}$ 's treatment to address the "problem of 
widespread wild animal suffering." They provide no specific empirical framework or method, however. Yet that is what would be needed to create an evolutionarily and ecologically motivated science of animal welfare no longer confined to animals in captivity.

Animal welfare science can be readily extended to include wild animals. Yet none of the seventeen commentators on $\mathrm{Ng}$ were welfare scientists. The points $\mathrm{Ng}$ makes are well known in that field. Most practitioners, for example, now accept that the subjective experience of animals - i.e., animal sentience - is a valid object of scientific investigation (Mellor et al. 2020; Yeates and Main 2008; Duncan 2002).

The distinction between captivity and freedom is often overstated; there is no intrinsic difference between wild and captive animals (Browning and Veit 2021). We should focus on how to extend the current methods of welfare science to measure, assess, and improve animal welfare in the wild. This is not to deny that new methods are needed for assessing the welfare of animals outside captivity. More evolutionary and ecological considerations should be integrated into the science of animal welfare (Veit and Browning 2020). Anecdotal evidence from ethologists and ecologists studying animals in the wild may be a useful starting point (Browning 2017). There may well be reciprocity too: Some of the knowledge gained from welfare assessment in the wild may also prove applicable to animals in captivity.

\section{References}

Beausoleil, N. J. (2020). I am a compassionate conservation welfare scientist: Considering the theoretical and practical differences between Compassionate Conservation and Conservation Welfare. Animals 10(2), 257.

Beausoleil, N. J., D. J. Mellor, L. Baker, S. E. Baker, M. Bellio, A. S. Clarke, A. Dale, S. Garlick, B. Jones, A. Harvey, B. J. Pitcher, S. Sherwen, K. A. Stockin, and S. Zito (2018). "Feelings and Fitness" not "Feelings or Fitness" - the raison d'être of Conservation Welfare, which aligns conservation and animal welfare objectives. Frontiers in Veterinary Science 5(296).

Browning, H. (2017). Anecdotes can be evidence too. Animal Sentience 2(16), 13.

Browning, H. (2019). The natural behavior debate: Two conceptions of animal welfare. Journal of Applied Animal Welfare Science 23(3), 325-337.

Browning, H. (2020). If I Could Talk to the Animals: Measuring Subjective Animal Welfare. Ph. D. thesis, Australian National University.

Browning, H. and W. Veit (2021). Freedom and animal welfare. Animals 11(4), 1148.

Dawkins, M. (2015). Animal welfare and the paradox of animal consciousness. Advances in the Study of Behavior 47, 5-38.

Dawkins, M. S. (1998). Evolution and animal welfare. The Quarterly Review of Biology 73(3), $305-328$.

Duncan, I. J. (2002). Poultry welfare: Science or subjectivity? British Poultry Science 43(5), 643652.

Groff, Z. and Y.-K. Ng (2019). Does suffering dominate enjoyment in the animal kingdom? An update to welfare biology. Biology \& Philosophy 34(4), 1-16.

Harvey, A. M., N. J. Beausoleil, D. Ramp, and D. J. Mellor (2020). A Ten-Stage Protocol for Assessing the Welfare of Individual Non-Captive Wild Animals. Animals, 10(1), 148. 
Horta, O. (2010). Debunking the idyllic view of natural processes: Population dynamics and suffering in the wild. Télos 17(1), 73-88.

Johannsen, K. (2016). Animal welfare at home and in the wild. Animal Sentience 7(10).

Johannsen, K. (2020). Wild Animal Ethics: The Moral and Political Problem of Wild Animal Suffering (1 ed.). Routledge.

Mellor, D. J., N. J. Beausoleil, K. E. Littlewood, A. N. McLean, P. D. McGreevy, B. Jones, and C. Wilkins (2020). The 2020 Five Domains model: Including human-animal interactions in assessments of animal welfare. Animals 10(10), 1870.

Ng, Y.-K. (1995). Towards welfare biology: Evolutionary economics of animal consciousness and suffering. Biology and Philosophy 10(3), 255-285.

$\mathrm{Ng}$, Y.-K. (2016). How welfare biology and commonsense may help to reduce animal suffering. Animal Sentience 7(1).

Soryl, A. A., A. J. Moore, P. J. Seddon, and M. R. King (2021). The Case for Welfare Biology. Journal of Agricultural and Environmental Ethics 34(2), 7.

Tomasik, B. (2015). The Importance of Wild-Animal Suffering Wild Animal Suffering and Intervention in Nature: Studies and Research Contributions. Relations: Beyond Anthropocentrism (2), 133-152.

Tomasik, B. (2017, online posting). Habitat loss, not preservation, generally reduces wild animal suffering.

Veit, W. (2021). Health, Agency, and the Evolution of Consciousness. Ph.D. thesis, University of Sydney. Manuscript in preparation.

Veit, W. and H. Browning (2020). Perspectival pluralism for animal welfare. European Journal for Philosophy of Science 11(1).

Yeates, J. W. and D. Main (2008). Assessment of positive welfare: A review. The Veterinary Journal 175(3), 293-300. 